\title{
Pemberdayaan Masyarakat dalam Upaya Meningkatkan Derajat Kesehatan Lanjut Usia di Desa Kangkung, Mranggen, Demak
}

\author{
Edy Soesanto1, Heryanto Adi Nugroho1, Ernawati Ernawati1, Siti Aisah1, Dewi \\ Setyowati', Much Nur Kharistna Al Jihad1
}

1 Universitas Muhammadiyah Semarang, Indonesia

\section{Informasi Artikel}

Riwayat Artikel:

- Submit 13 Mei 2021

- Diterima 8 Juni 2021

- Diterbitkan 10 Juni 2021

Kata kunci:

Pemberdayaan; pelatihan; posyandu; lansia

\section{PENDAHULUAN}

Kemajuan ekonomi, perbaikan lingkungan hidup dan majunya ilmu pengetahuan dan

\section{Abstrak}

Kemajuan ekonomi, perbaikan lingkungan hidup dan majunya ilmu pengetahuan dan teknologi khususnya di bidang kesehatan, mampu meningkatkan umur harapan hidup (life expectancy). Dengan meningkatnya angka harapan hidup lanjut usia yang semakin tinggi, maka dibutuhkan kualitas hidup yang lebih bermakna di bandingkan dengan kualitas hidup yang sekarang yang masih relatif rendah, khususnya masalah kesehatan. Untuk meningkatkan kesejahteraan khususnya sosial, ekonomi , kesehatan dan kemampuan lanjut usia, perlu di selenggarakan suatu suatu program yang berbentuk pelayanan dan pengembangan kelembagaan yang menangani masalah-masalah tersebut. Pos Pembinaan Terpadu (Posbindu) Lanjut Usia merupakan salah satu wadah yang dapat membantu masyarakat melakukan upaya peningkatan dan pencegahan terhadap masalah kesehatan yang dialami oleh lanjut usia sehingga tercapai kualitas hidup yang optimal, tetapi pelaksanaannya seringkali tidak berjalan dengan baik karena dukungan masyarakat yang masih kurang, keterbatasan jumlah kader, sulitnya mencari kader yang memiliki waktu luang. Tujuan kegiatan ini adalah untuk meningkatkan peran serta masyarakat dalam upaya meningkatkan derajat kesehatan lanjut usia melalui rekruitmen dan pelatihan kader kesehatan. Kegiatan ini melibatkan pemerintah desa,tokoh masyarakat, kader kesehatan dan para lansia di dusun Karang, desa Kangkung, Mranggen, Demak. Kegiatan dilakukan dengan tiga tahap yaitu perencanaan, pelaksanaan, evaluasi dan tindak lanjut. Perencanaan dilakukan untuk mengedukasi masyarakat tentang pentingnya posbindu lanjut usia dan penyakit yang lazim terjadi pada lanjut usia yang perlu penanganan khusus dan kontinyu. Pelaksanaan rekruitmen dan pelatihan kader untuk membekali kader dalam pelayanan posbindu. Kegiatan dilaksankan dengan baik dan mendapat respon kooperatif, antusias dan aktif setiap kegiatan dilakukan. pemerintah desa, masyarakat dan Puskesmas Mranggen I mendukung keberadaan posbindu. untuk mengendalikan dan mengontrol masalah kesehatan yang dialami oleh lanjut usia khususnya penyakit degeneratif.

Corresponding author:

Edy Soesanto

edysoes@unimus.ac.id

SALUTA: Jurnal Pengabdian Kepada Masyarakat, Vol 1 No 1, Juni 2021

DOI: https://doi.org/10.26714/sjpkm.v1i1.8537 
kecenderungan akan meningkat lebih cepat. Dengan meningkatnya angka harapan hidup lanjut usia yang semakin tinggi, maka dibutuhkan kualitas hidup yang lebih bermakna di bandingkan dengan kualitas hidup yang sekarang yang masih relatif rendah, khususnya masalah kesehatan. Berdasarkan survey dari Badan Pusat Statistik (BPS) jumlah lanjut usia di Indonesia sebanyak 26,82 juta jiwa atau 9,92\% (Sosial, 2020). 9,80\% lanjut usia tinggal sendiri, di mana persentase lanjut usia perempuan yang tinggal sendiri hampir tiga kali lipat dari lanjut usia laki-laki (14,13\%berbanding 5,06\%).

Keadaan lanjut usia di Indonesia, sebanyak $2.426 .191(15 \%)$ terlantar, dan sebanyak 4.658.279 $(28,8 \%)$ rawan terlantar, dari sisi kesehatan masih ada sekitar separuh lanjut usia yang mengalami keluhan kesehatan selama sebulan terakhir. Angka kesakitan lanjut usia cenderung menurun setiap tahun. Pada tahun 2018, sekitar 24 dari 100 lanjut usia sakit dalam sebulan terakhir, hampir 1 dari 4 lanjut usia merokok selama sebulan terakhir. Penyakit terbanyak adalah penyakit sendi $(52,3 \%)$, hipertensi $(38,8 \%)$, anemia $(30,7 \%)$ dan katarak (23\%), penyakit-penyakit tersebut merupakan penyebab utama disabilitas pada lanjut usia. Jaminan kesehatan belum sepenuhnya dapat menjangkau seluruh lanjut usia. Sekitar 26,41 persen penduduk lanjut usia belum memiliki jaminan kesehatan.

Jumlah lanjut usia di Kabupaten Demak sebanyak 144624 jiwa atau sebesar 11,5\% dari total penduduk (Sosial, 2020), sekitar 60 - 85\% para lanjut usia di kabupaten Demak tinggal di daerah perdesaan. Menurut hasil pendataan yang dilakukan oleh Badan Pemberdayaan Masyarakat dan KB Kab. Demak pada tahun 2019, desa Kangkung kecamatan Mranggen merupakan daerah pedesaan, mayoritas penduduk bekerja sebagai petani, dan pengrajin mebelair, sebagian besar perempuan bekerja sebagai buruh pabrik. Mayoritas pendidikan penduduk adalah tamatan sekolah dasar sebesar 57,6\%, Sosial ekonominya termasuk katagori menengah kebawah, sebagian besar masyarakatnya adalah buruh (65\%) (Demak, 2019).

Potensi desa yang masih bisa diandalkan adalah pemanfaatan pekarangan dan kebun dengan penanaman empon-empon, pisang dan tanaman musiman serta masih banyaknya lahan kosong yang belum dimanfaatkan oleh penduduk secara maksimal. Jarak antara desa dengan pusat pelayanan kesehatan kurang lebih $4 \mathrm{~km}$, jumlah usia lanjut sebanyak 558 jiwa (usia 60 tahun keatas) atau sebesar 6,2\% dari total penduduk desa Kangkung 8991 jiwa. jumlah lanjut usia yang tidak/belum pernah sekolah sebesar 30\%, yang tidak tamat SD sebesar $42 \%$ dan yang tamat SD sebesar $21,27 \%$ dan permasalahan akan timbul karena jumlah lanjut usia yang tidak mempunyai kemampuan membaca dan menulis sebesar 30\% (Kab.Demak, n.d.) .

Dari data kunjungan di Puskesmas Mranggen penyakit terbanyak yang diderita Lanjut usia adalah hipertensi $(57 \%)$, penyakit sendi $(40 \%)$, anemia (30\%) dan katarak (15\%) dan penyakit degeneratif lainnya (8\%) (Dinkes Kab. Demak, 2019). Untuk meningkatkan kesejahteraan khususnya sosial, ekonomi , kesehatan dan kemampuan lanjut usia, perlu di selenggarakan suatu suatu program yang berbentuk pelayanan dan pengembangan kelembagaan yang menangani masalah-masalah tersebut.

Pos Pembinaan Terpadu (Posbindu) Lanjut Usia merupakan salah satu wadah yang dapat membantu masyarakat melakukan upaya peningkatan dan pencegahan terhadap masalah kesehatan yang dialami oleh lanjut usia sehingga tercapai kualitas hidup yang optimal dan kemandirian pada lanjut usia dengan suatu pendekatan 
program pelayanan yang difokuskan pada program terpadu (Integrated program). Desa kangkung telah memiliki pos pelayanan terpadu (posbindu) lanjut usia di tiap RW (6 posbindu) tetapi pelaksanaannya tidak berjalan dengan baik karena dukungan masyarakat yang masih kurang, keterbatasan jumlah kader, sulitnya mencari kader yang memiliki waktu luang karena sebagian besar bekerja sebagai buruh pabrik dan belum semua kader mampu menjalankan perannya dengan baik (DS Fatmawati, 2019; E Soesanto, 2020).

Sejalan dengan hal tersebut maka program studi Keperawatan Universitas Muhammadiyah Semarang mengadakan kegiatan pelatihan dan rekruitmen kader posbindu lanjut usia agar pemberdayaan dan peran serta aktif masyarakat di desa Kangkung, Mranggen Demak dapat menghasilkan kemandirian masyarakat, kemampuan untuk mengidentifikasi masalah yang terjadi serta membuat perencanaan dan upaya pemecahan masalah dengan memanfaatkan potensi yang ada tanpa tergantung pada bantuan dari luar.

\section{METODE}

Kegiatan pengabdian kepada masyarakat ini dilaksanakan pada bulan Januari februari 2019 setiap hari minggu di dusun Karang, desa Kangkung Mranggen Demak, yang mencakup 2 RW dan 11 RT dengan melakukan kegiatan pelatihan dan rekruitmen kader posbindu lanjut usia, masing masing RT diwakili oleh 3 orang dan kegiatan ini dipusatkan di RW 5 dukuh Karang. Materi pelatihan terdiri dari materi dasar, materi inti, materi penunjang dan simulasi. Metode pelaksanaan pengabdian kepada masyarakat ini terdiri dari:

\section{Perencanaan}

Kegiatan ini didasari oleh hasil penelitian yang telah dilakukan oleh tim maka pada bulan Januari 2019 dilakukan pendekatan dengan berbagai tokoh masyarakat (tokoh agama, kepala desa, bidan desa, para kader yang ada dan pihak Puskesmas) untuk mendapatkan gambaran, masukan dan saran untuk menghidupkan kembali kegiatan posyandu lanjut usia yang pernah ada di desa Kangkung.

Langkah selanjutnya tim melakukan koordinasi dengan kepala puskesmas, pemegang program PTM, kepala desa, ketua RW/RT di dukuh Karang, Kangkung, Demak. Kegiatan pelatihan dan rekruitmen kader kesehatan ini disepakati dilaksanakan pada bulan Februari 2019 setiap hari minggu selama 4 kali pertemuan mulai jam 08.00 - 11.30. Kegiatan selanjutnya adalah melakukan rekruitmen calon kader disetiap RT (maksimal 3 orang) dengan persyaratan sukarela, memiliki waktu luang dan memiliki komitmen tinggi untuk melaksanakan semua kegiatan pelaksanaan posyandu lanjut usia.

\section{Pelaksanaan}

Pelaksanaan kegiatan pengabdian kepada masyarakat ini dilakukan melalui beberapa tahapan, diantaranya adalah:

\section{Brainstorming.}

Brainstorming dilakukan dengan mengundang semua pemangku kepentingan seperti: kepala desa, kepala dusun, ketua RW-RT, tokoh masyarakat, tokoh agama dan para lanjut usia. Pelaksanaannya diadakan di gedung balai desa pada tanggal 15 Januari 2019 jam 16.00 , tujuan dari kegiatan ini adalah untuk mengidentifikasi permasalah yang menyebabkan pelaksanaan posyandu lanjut usia di desa Kangkung terhenti, mencari solusi agar pelaksanaan posyandu lanjut usia bisa diaktifkan kembali. Kegiatan sosialisasi ini lebih menekankan komitmen bersama semua elemen yang ada 
dimasyarakat untuk mengaktifkan kembali posyandu lanjut usia yang telah ada.

Pelatihan dan penyegaran kader kesehatan.

Pelaksanaan pelatihan dan penyegaran kader dilakukan sebanyak 4 kali setiap hari Minggu di bulan Februari 2019 mulai jam 08.00-12.00 bertempat di gedung Balai Desa Kangkung. Pelatihan dan penyegaran kader posyandu lanjut usia ini diikuti oleh 28 peserta. Materi pelatihan dan penyegaran kader meliputi: Proses Menua dan perubahan yang terjadi pada lanjut usia, masalah kesehatan yang terjadi pada lanjut usia khususnya Penyakit Tidak Menular (PTM), upaya pencegahan dan perawatan PTM yang dapat dilakukan masyarakat, manajemen posyandu, komunikasi efektif dan role play posyandu lanjut usia.

Pelaksanaan posyandu lanjut usia.

Setelah selesai melakukan pelatihan dan penyegaran kader disekapati pelaksanaan kegiatan posyandu lanjut usia disesuaikan dengan pelaksanaan sebelumnya yaitu setiap hari Minggu Legi disetiap bulannya karena para lanjut usia sebelumnya telah terbiasa dengan jadwal tersebut sehingga memudahkan untuk menggerakkannya.

\section{Evaluasi dan Rencana Tindak Lanjut}

Kegiatan pelatihan dan penyegaran kader posyandu lanjut usia ini akan dievaluasi setiap pelaksanaan posyandu lanjut usia. Evaluasi yang dilakukan meliputi keaktifan dan kehadiran kader, jumlah lanjut usia yang hadir, pelaksanaan posyandu lanjut usia, pelaksanaan manajemen posyandu, penggunaan sarana prasarana, peralatan yang digunakan, pencatatan dan pelaporan pelaksanaan posyandu. setelah dilakukan evaluasi disetiap pelaksanaan posyandu disepakati setiap 3 bulan sekali dilakukan penyegaran pada kader dengan topik yang berbeda sesuai dengan kesepakatan.

\section{HASIL DAN PEMBAHASAN}

Pengabdian kepada masyarakat yang dilakukan oleh tim dosen keperawatan Universitas Muhammadiyah Semarang sesuai dengan hasil kesepakatan bersama para pemangku kepentingan yang menghendaki agar posyandu lanjut usia yang tidak aktif dapat segera diaktifkan kembali karena kegiatan posyandu lanjut usia selama ini sangat membantu masyarakat khususnya lanjut usia melakukan upaya pemantauan kesehatannya. Pelaksanaan posyandu lanjut usia di desa Kangkung sempat terhenti karena beberapa kader sering tidak hadir dengan alasan banyak kerjaan dirumah dan tanggung jawab kader banyak sehingga jumlah kader saat pelaksanaan posyandu lanjut usia menjadi terbatas dan menyebabkan pelayanan tidak maksimal.

Peningkatan pelayanan kesehatan kepada lanjut usia diperlukan untuk mewujudkan lanjut usia yang sehat, berkualitas, dan produktif di masa tuanya (Azizah Nurul Karohmah, 2017). Dukungan semua pihak sangat membantu menguatkan lanjut usia untuk lebih memanfaatkan posyandu lanjut usia dan dapat memberikan semangat pada kader kesehatan untuk memberikan pelayanan yang terbaik (Soesanto et al., 2018). Hal ini juga telah dilakukan oleh masyarakat desa kangkung pada pertemuan brainstorming yang telah berkomitmen kembali untuk memberikan dukungan secara penuh agar posyandu lanjut usia dapat aktif kembali.

Pelaksanaan posyandu lanjut usia agar dapat berjalan dengan baik dalam memberikan pelayanan kepada masyarakat khususnya lanjut usia diperlukan kader kesehatan yang memiliki komitmen dan 
loyalitas yang tinggi, kader memiliki peran sentral dalam pelaksanaan pelayanan di posyandu lanjut usia (E Soesanto, 2020). Kader merupakan penggerak masyarakat yang memiliki pengetahuan tentang kesehatan lanjut usia dan kemampuan meningkatkan kualitas kesehatan lanjut usia. Kader juga memberikan motivasi kepada lanjut usia untuk memanfaatkan fasilitas kesehatan dan senantiasa melakukan aktifitas sosial (Punyakaew, A., Lersilp, S., \& Putthinoi, 2019). Oleh karena itu rekruitmen dan pelatihan kader merupakan suatu hal yang sangat penting untuk menghidupkan kembali posyandu lanjut usia yang sudah tidak aktif agar kembali aktif.

Pelatihan kader posyandu lanjut usia dapat meningkatkan pengetahuan dan ketrampilan dalam melaksanakan posyandu (Mega Arianti Putri, 2020). Penyegaran kader dapat memberikan refresh materi kepada para kader dan memberikan pemahaman terkait peran kader, penanganan penyakit yang lazim terjadi pada lanjut usia dan cara melakukan komunikasi yang efektif sehingga bisa memberikan motivasi dan menyiapkan kader untuk memberikan pelayanan kesehatan lanjut usia di posyandu lanjut usia (Ihsana El Khuluqo, 2020). Pada setiap sesi materi kepada peserta diberi kesempatan untuk memberikan pertanyaan dan jawaban di diskusikan secara bersama berdasarkan pengalaman yang dialami masing-masing peserta. Peserta bersemangat menceritakan pengalamannya dan antusias dalam mendengarkan materi yang disampaikan.

Pelaksanaan posyandu lanjut usia di desa Kangkung, Mranggen dilaksanakan sebulan sekali setiap hari Minggu Legi mulai jam 07.00 - 11.00. Sehari sebelum dilaksanakan kegiatan posyandu lanjut usia para kader melakukan pertemuan guna mempersiapkan pelaksanaan posyandu lanjut usia yang meliputi pembagian kerja untuk penanggungjawab masing-masing kegiatan seperti senam lanjut usia diawal kegiatan, pembagian tugas di masingmasing meja, pembuatan PMT, memberitahu lanjut usia melalui pengurus RT dan pengeras suara di mushola, menyiapkan materi penyuluhan, mempersiapkan kebutuhan yang digunakan dalam posyandu lanjut usia.

Kegiatan yang dilakukan dalam pelaksanaan posyandu lanjut usia sesuai dengan sistem pelayanan 5 meja, yaitu pendaftaran, menimbang berat badan (BB) atau mengukur tinggi badan, pemeriksaan kesehatan, konseling atau penyuluhan, pemberian PMT, pemeriksaan laboratorium dan senam lanjut usia serta pengajian. Pelaksanaan posyandu lanjut usia mendapat tanggapan yang luar biasa dari pemerintah desa, masyarakat dan Puskesmas Mranggen I, terbukti angka kunjungan lanjut usia di posyandu lanjut usia mencapai 80\% (198 peserta) dari 247 lanjut usia. Dari 198 peserta hanya 30\% yang sehat dan selebihnya memiliki masalah kesehatan. Masalah kesehatan yang paling banyak diderita lanjut usia adalah hipertensi (40\%), Nyeri sendi (30\%), DM (15\%) dan penyakit lainnya (15\%). Sebagian besar lanjut usia merasa senang dengan dimulainya lagi posyandu lanjut usia, dukungan keluarga dan masyarakat sangat tinggi hal ini terlihat dari banyaknya anggota keluarga yang ikut mengantar para lanjut usia datang ke posyandu lanjut usia dan menunggu sampai selesainya kegiatan.

\section{SIMPULAN}

Kegiatan pengabdian kepada masyarakat melalui pelatihan dan rekruitmen kader kesehatan mampu memotivasi kader untuk kembali memebrikan pelayanan kesehatan pada lanjut usia melalui kegiatan posyandu lanjut usia. Beberapa lanjut usia ditemukan memiliki masalah kesehatan khususnya penyakit degeneratif. Masyarakat 
khususnya para lanjut usia sangat antusias menyambut dibukanya kembali kegiatan posyandu lanjut usia yang telah lama tidak aktif. Kegiatan pelayanan kesehatan yang dekat, mudah diakses, murah, berkesinambungan sangat diperlukan oleh lanjut usia guna meningkatkan derajat kesehatan dan kualitas hidup yang lebih bermakna.

\section{SARAN}

Kepada Pemerintah Desa kangkung, Mranggen dan Puskesmas Mranggen I diharapkan bisa membina organisasi Posbindu lanjut usia desa Kangkung, Mranggen dalam hal pendanaan operasional organisasi dan peningkatan pemahaman masyarakat untuk mendorong masyarakat aktif mengikuti kegiatan posyandu lanjut usia sehingga kualitas hidupnya dapat dicapai secara optimal.

\section{UCAPAN TERIMA KASIH}

Mengucapkan terimakasih kepada Kepada Pemerintah Desa kangkung, Mranggen, Puskesmas Mranggen I, dan Posbindu lanjut usia desa Kangkung.

\section{REFERENSI}

Azizah Nurul Karohmah, I. (2017). Peran Posyandu Lansia Dalam Meningkatkan Kesejahteraan Lanjut Usia Di Posyandu Lansia Sejahtera Kelurahan Pasirmuncang. Jurnal Untirta, 2(2), 116-213.

Demak, B. P. M. dan K. K. (2019). Demak pada tahun
2019. Bapermas Kab. Demak.

Dinkes Kab. Demak, P. M. (2019). Laporan SP2TP Puskesmas Mranggen tahun 2019.

DS Fatmawati, E. S. (2019). Increased the Intensity of Elderly Visit to posyandu. South East Asia Nursing Research, 1(3), 137-141.

E Soesanto, N. A. (2020). The Role of Volunteers in Improving Services in Elderly Integrated Service Centers. South East Asia Nursing Research, 2(1), 22-26.

Ihsana El Khuluqo, T. N. (2020). Pelatihan Dan Pendampingan Kader Posyandu Lansia Di Wilayah Kerja Puskesmas Cimuning. Jurnal Pemberdayaan Masyarakat Universitas Al Azhar Indonesia, 2(1), 1-5.

Kab.Demak, B. (n.d.). Kecamatan Mranggen Dalam Angka tahun 2019. BPS Kab. Demak.

Mega Arianti Putri, S. S. (2020). Pembinaan Kader Lansia Dalam Upaya Peningkatan Pelayanan Kesehatan Lansia. Journal of Community Engagement in Health, 3(2), 304-308.

Punyakaew, A., Lersilp, S., \& Putthinoi, S. (2019). Active ageing level and time use of elderly persons in a Thai suburban community. Occupational Therapy International, 2019(8), 1-8.

Soesanto, E., Istiarti, T., Pietojo, H., Semarang, U. M., Kesehatan, F., Universitas, M., Semarang, D., Magister, ), Kesehatan, P., Diponegoro, U., \& Abstrak, S. (2018). Praktik Lansia Hipertensi dalam Mengendalikan Kesehatan Diri di Wilayah Puskesmas Mranggen Demak. Praktik Lansia Hipertensi Dalam Mengendalikan Kesehatan Diri Di Wilayah Puskesmas Mranggen Demak, 5(2), 127-139. https://doi.org/10.14710/jpki.7.3.127-139

Sosial, S. S. P. dan K. (2020). Statistik Penduduk lanjut Usia 2020. BPS. 